\title{
Exploring the professionalization of respiratory therapy in Canada
}

\author{
Marco Zaccagnini, PhD (c), MSc, RRT-CCAA, FCSRT ${ }^{1,2}$, André Bussières, DC, PhD ${ }^{1,2,3}$, Peter Nugus, MA(Hons), PhD ${ }^{4,5}$, \\ Andrew West, EdD, FCSRT ${ }^{6}$, Aliki Thomas, OT (c), PhD $^{1,2,4}$
}

\begin{abstract}
M Zaccagnini, A Bussières, P Nugus, A West, A Thomas. Exploring the professionalization of respiratory therapy in Canada. Can J Respir Ther 2021;57:129-137. doi: 10.29390/cjrt-2021-046.

Introduction: A recurrent challenge facing respiratory therapists (RTs) is their legitimacy as professionals. RTs are often referred to as technologists, vocationalists, or technicians and must often justify their status as full professionals rather than "professional technicians". There is currently little exploration of what it means to be a profession and the process of professionalization in respiratory therapy.

Approach: Drawing from sociological theory, the purpose of this paper is to discuss the professionalization of respiratory therapy in Canada using Andrew Abbott's theory, the "system of professions". We will use this theory as a lens to propose areas of consideration for professional development regarding two pervasive themes in the respiratory therapy community, RTs' specialized body of knowledge and professional autonomy.

Findings: Abstract knowledge is believed to be essential in the evolution from occupation to profession and is valuable to a profession in three ways: it can influence the profession's legitimacy, it can be used for conducting research, and it promotes higher education. RTs possess jurisdictional professional autonomy within Canada. The privilege of self-regulation allows RTs to act according to their knowledge and judgement without direct oversight from other professions.

Conclusion: Based on Abbott's theoretical position, RTs can rightly justify their position as professionals. However, RTs need to acknowledge that professionalization is a dynamic and continuous process that requires creative changes to innovate within the profession and support future efforts to reinforce their position as professionals. Throughout this paper, we offer suggestions for how RTs can contribute to the ongoing professionalization of respiratory therapy.
\end{abstract}

Key Words: professional practice; respiratory therapy; allied health personnel; social theory; societies; professionalization

\section{INTRODUCTION}

In Canada, there are over 12,000 practicing respiratory therapists (RTs) who possess clinical expertise, knowledge, and skills in cardiorespiratory health care [1-3]. Despite the involvement of RTs across a broad range of health services, public knowledge of the respiratory therapy profession remains superficial. This is in part perpetuated by variability in the respiratory therapy workforce globally. For instance, outside of North America, only a few countries have the services of RTs incorporated into their health care systems. In countries without RTs, professionals such as physiotherapists, nurses, or physicians who chose to specialize in the respiratory field typically provide respiratory care. Respiratory therapy is in a state of transition worldwide $[4,5]$. Only recently, amidst the global changes caused by the coronavirus (COVID-19) pandemic, have RTs been featured as key members of interprofessional teams and critical to the health care system [6-10].

A recurrent challenge facing RTs is the inconsistency regarding their legitimacy as professionals. They are often referred to as technologists, vocationalists, or technicians and must often justify their status as full professionals rather than "professional technicians" [11]. There is currently little exploration of what it means to be a profession and the process of professionalization in the context of respiratory therapy. A deeper and theory-driven inquiry regarding the process of RTs professionalization journey may provide valuable insights into how it might evolve to meet its societal obligations and continue to develop as a profession.

The purpose of this paper is to discuss the professionalization pathway of respiratory therapy in the Canadian context. We use Andrew Abbott's [12] "system of professions" theory to propose areas of consideration for the future professionalization of RTs regarding two pervasive themes in the respiratory therapy community, namely RTs' specialized body of knowledge and professional autonomy.

\section{The emergence of respiratory therapy in Canada}

Respiratory therapy is a relatively young area of practice. Respiratory therapy became officially established in 1947 in the United States followed by Canada in 1964. Canadian respiratory therapy was born out of a need during the post-World War II era when the Canadian health care system was undergoing rapid technological, environmental, and societal changes. Spurred by the poliomyelitis (polio) epidemic of 1950-1954, new technology was appearing rapidly. These innovations included developing positive pressure mechanical ventilators as an alternative to negative pressure ("iron lung") ventilators, new technology to alleviate patient's hypoxemia, and new pharmacological agents in anesthetics, bronchodilator therapy, and broad-spectrum antibiotics [13]. The emergence of this new

\footnotetext{
${ }^{1}$ School of Physical and Occupational Therapy, McGill University, Montréal, QC, Canada

${ }^{2}$ Centre for Interdisciplinary Research in Rehabilitation of Greater Montréal, Montréal, QC, Canada

${ }^{3}$ Département Chiropratique, Université du Québec à Trois-Rivières, Trois-Rivières, QC, Canada

${ }^{4}$ Institute of Health Sciences Education, McGill University, Montréal, QC, Canada

${ }^{5}$ Department of Family Medicine, McGill University, Montréal, QC, Canada

${ }^{6}$ The Canadian Society of Respiratory Therapists, Saint John, NB, Canada

Correspondence: Aliki Thomas, McGill University, 3654 Promenade Sir William Osler, Montréal, QC H3G 1Y5, Canada. E-mail: aliki.thomas@mcgill.ca
}

Published online at https://www.cjrt.ca on 8 October 2021 
technology required physicians to seek assistants to help them manage and apply the new technology to patients, thereby creating the "oxygen orderly" occupation. These orderlies were individuals with various backgrounds (e.g., war veterans, engineers, surgeon's assistants) who held various positions throughout the hospital (e.g., in the engineering departments) and possessed some mechanical knowledge of gas distribution systems [13]. The orderly's educational emphasis in the respiratory field was on the technical knowledge needed to provide a safe oxygen delivery service rather than acquiring medical literacy skills related to cardiopulmonary diseases and their treatments. The tasks of orderlies included cleaning, managing, storing, and delivering high-pressure oxygen cylinders and related oxygen equipment to the patient's bedside, ensuring oxygen humidity bottles were filled with water, and servicing anesthesia and mechanical ventilators [13]. As technology continued to expand, so too did the diversity of the tasks performed by the oxygen orderly. This expansion resulted in physicians (notably anesthesiologists and respirologists) relying increasingly on the oxygen orderlies [13].

In June of 1961, the movement to officially define and formalize the inhalation technician (formally known as oxygen orderly) occupation began. The Canadian Anesthesia Society (CAS) and the Canadian Medical Association (CMA) created the pilot committee on inhalation therapy. The mandate of the CAS-CMA was to make recommendations on the minimum educational qualifications required to practice as a technician and to establish standards of care [14]. The CAS-CMA concluded that inhalation technicians require 1 year of technical and academic training within the hospital under direct medical supervision to remain an asset in Canadian hospitals $[14,15]$. These physician groups drove the creation of respiratory therapy, contributed to the licensing exam, and supported the development of dedicated inhalation therapy schools across Canada. Simultaneously, the inhalation technicians established the Canadian Association of Inhalation Therapists (CAIT) in 1964 to act as a certification agent in response to medical employers' demands for educational standardization. The CAIT also created a scientific journal dedicated to empirical research of inhalation technology of Canada: The Canadian Inhalation Therapy Journal [16] and officially changed the professional title from inhalation technician to respiratory therapist. The emphasis on "therapist" suggested that RTs were steadily becoming more clinically and patient-oriented rather than being merely technical support.

In Canada, the respiratory therapy curricula evolved to include physiology and pathology, a greater focus on clinical observation and diagnosis, and explicit content on understanding and selecting techniques to fulfill therapeutic objectives [13]. As a result, in 1967, hospital training programs began to integrate with educational institutions. The first Canadian community college-hospital-affiliated training program appeared in Edmonton, Alberta, at the Northern Alberta Institute of Technology. College-based programs at Fanshawe College in London, Ontario, and the Toronto Institute of Medical Technology, Toronto, Ontario, quickly followed [13]. There is no documented information regarding why these programs chose to merge with technical schools. It may have been due to RTs identifying with the school's technological orientation or simply a matter of availability. The education level for Canadian RTs was deemed appropriate at the college-diploma level [14, 15]. Despite the numerous developments of the respiratory therapy profession over time, it is unclear at which point and how the occupation of an inhalation technician became the profession of respiratory therapy. Sociologist's Andrew Abbott's theory of the "system of professions" [12] may help clarify aspects of professionalization within the respiratory therapy profession.

\section{Process of professionalization}

Professionalization is the social process and evolutionary path by which an occupation evolves through an occupational hierarchy [17, 18]. This process is used to garner professional status, expertise, establish a market for specific services, and gain a heightened social positioning [18-23]. Professionalization is a broad and complex area of study often found in sociology (i.e., the study of social life) because work encompasses a large part of what it means to be a social being [24].
A review of the many theories of professionalization is beyond the scope of this article and has been published elsewhere (see Martimianakis et al. [25]). For the purposes of this discussion, we applied Abbott's [12] theory of professionalization as it is the most recent comprehensive theory of professions. Before Abbott, theories of professionalization mostly focused on how professions were organized, how much power they held, and how they developed unidirectionally. On the other hand, Abbott argued that to understand the progress of a profession, we must consider its social and professional surroundings, and the process in which it interacts with those surrounding [26-28].

\section{The system of professions}

Andrew Abbott, in his "System of Professions", postulated that professions do not develop in isolation from one another and that professionalization is not a unidirectional process but a dynamic process [12]. Specifically, professions constantly fluctuate because they develop and exist within a complex and expansive professional, social, and economic environment. Abbott revolutionized the study of professions by suggesting that they be studied within a broader ecological and evolving system to better understand their status. He suggested that the focus be on four interacting elements that may influence the development, maintenance, and fate of professions: work, jurisdiction, competition, and abstract knowledge [12]. We describe each one next.

\section{Work}

Professionals are tasked with addressing complex human problems that require specific domains of expertise. They must demonstrate their work expertise through a logical sequence of tasks and by engaging in activities that comprise the classification of a problem and by reasoning on and then acting on a given problem. This sequence represents the "how" a professional performs their work. It is the "how" professionals work and the cognitive structure (i.e., the sequence of logic and engagement) required to solve a problem that justifies their claims of jurisdiction.

\section{Jurisdiction}

Abbott defines jurisdiction as the vital link between a profession and the tasks that compose its work. Jurisdiction (or control over work) is where a profession solicits society's recognition of its cognitive structure through exclusive rights (e.g., professional autonomy, public payments, rights of self-discipline) [12]. However, claiming jurisdiction is only possible in three areas: the workplace, public opinion, and the legal system (e.g., legislation). Together, these three jurisdictions create temporary stability in the profession because its members convey an image of a well-defined boundary surrounding the profession. However, these jurisdictions are never permanent and are constantly under competitive pressure in a system of professions such as when a task or clinical expertise is shared by two different professions, like complementary and alternative medicine, who may advocate for a jurisdiction to independently treat patients who are traditionally cared for by physicians [29].

\section{Competition}

While jurisdiction is the core tenet of a profession, by no means is it permanent. Professions "live" in proximity to one another in an interdependent system, in that each profession competes with others for work (e.g., "fight for turf") and the right to a jurisdiction. A shift in any profession will likely affect the entire system of professions [12]. One example of this shift appeared in the late 1980s when orthopedic surgeons decided to limit their practice to desirable aspects of their job rather than more routine ones (e.g., performing surgery instead of office counselling), paving the way for other providers (podiatrists) to claim this newly vacant jurisdiction $[30,31]$.

Competition for jurisdiction begins from external forces (i.e., opening or closing jurisdictions as a response to cultural and technological shifts) or internal forces (i.e., professionals reformulating their knowledge base, developing new knowledge, and (or) developing new skills to expand into other jurisdictions (e.g., nurse practitioners prescribing medication)) [32]. Achieving and maintaining professional jurisdiction requires that a profession controls the abstract knowledge needed to perform the tasks [12]. 


\section{Abstract knowledge}

Abstract knowledge is the key to establishing, expanding, and maintaining jurisdictional boundaries for any given profession. It consists of the formal and necessary information, principles, and concepts that are foundational for professionals to do their work [12, 33-37]. This knowledge is constantly evolving, transforming, and growing in ways that help to affirm its value. Certain members of the profession constantly scrutinize, discuss, document, and test this knowledge to ensure that health care professionals are equipped to fulfill society's ever-changing needs [38]. Abbott suggested that professionals who possess abstract knowledge provide the profession with a degree of power and prestige. Activities and services performed without this foundational abstract knowledge do not convey the same authoritative influence over individuals receiving the services [12]. Abstract knowledge is believed to be essential in the evolution from occupation to profession and is of value to a profession in three ways: (i) it can influence the profession's legitimacy, (ii) it is used to conduct research, and (iii) it promotes higher education, which we discuss next [12].

Abbott's system of profession underscores the notion that professionalization is complex and can be influenced by the economy, the organization, the local and national politics, culture, power differences, and society, often occurring in a non-linear fashion [12, 17, 39, 40]. We applied Abbott's theory as a lens to the respiratory therapy profession in Canada to understand its professionalization and make suggestions about future opportunities related to two major themes: RTs' specialized body of knowledge and professional autonomy.

Professionalization and abstract knowledge in respiratory therapy Abstract knowledge (i.e., specialized body of knowledge) is the key to maintaining the power and prestige needed to secure and retain jurisdictions. Abbott argued that "any occupation can obtain licensure (e.g., beauticians) or develop an ethics code (e.g., real estate). But only a knowledge system governed by abstraction can redefine its problems and tasks" [12] (p. 9). It is essential to consider all aspects of abstract knowledge (i.e., developing a specialized body of knowledge) to determine its influence on professionalization and how to further develop abstract knowledge to reinforce and evolve the professionalization of respiratory therapy.

The original motivation for training RTs (oxygen orderlies at the time) was to fill vacant technical positions caused by the rapid evolution of technology in hospitals. Many orderlies did not have preparatory education or continuing education and they trained on the job, focusing on the technical aspects of oxygen equipment. The educational emphasis on the technical component of work highlights that their foundational knowledge did not include any degree of abstraction. Knowledge tied to the routine use of a piece of equipment did not suggest any abstract decision-making; as such, the oxygen orderly's work was akin to a craft $[11,12]$. Oxygen orderlies were technicians (i.e., craftsmen) whose foundational knowledge and work were defined and confined to the machines and devices they serviced and maintained (i.e., mechanical ventilators). This link proved to be both a blessing and a curse in RTs' route towards professionalization as they used their understanding and use of mechanical ventilators as the springboards for creating their own abstract knowledge.

RTs were fortunate to have robust physician support in their formative years. Arguably, physicians' sponsorship was responsible for creating and elevating RTs' abstract knowledge base. A landmark article from the CMA proposed a training program for technicians, which included a blend of both technical and academic training-specifically including advanced training such as physiology and cardiovascular pathology but within the confines of the mechanical ventilator [14]. During the 1970s, RTs continued to create accredited educational programs, trained a substantial number of RTs, and successfully created hospital positions for individuals with respiratory therapy credentials. As RTs obtained regular positions in the hospital hierarchy, they looked for ways to distinctly evaluate and take care of hospital patients to safeguard their value as professionals and legitimize their role. At the time, other professions (e.g., physiotherapy) chose to cut ties with their routine use of machines (e.g., electrotherapy) and adopted a more patient-focused approach [41, 42]. It seemed that RTs leveraged their mechanical roots to define their abstract knowledge and claim their expertise.

RTs' mechanical roots proved invaluable when new technological innovations in medicine allowed them to extend their mechanical ventilator knowledge and skills into new categories of respiratory assistance $[11,13]$. This assistance included the routine use of positive pressure ventilation and the routine application of positive end-expiratory pressure (PEEP) to treat respiratory failure and oxygenation [43]. These modalities became widespread in Canadian hospitals and required a precise calibration of the pressure level specific to each patient case and required safe and constant monitoring and regulation of the applied positive pressure. These techniques became a curative modality that required expert knowledge that was directly rooted in the daily use of mechanical ventilators [11, 13]. This modality revolutionized the care for patients and revolutionized RTs' tasks. Finally, the mechanical ventilator work of RTs evolved from a technical aspect to a therapeutic, patient-centred modality that succeeded in abstracting some of the RTs' knowledge. This abstract knowledge successfully positioned RTs to fill a vacancy in knowledge and allowed them to achieve a degree of jurisdiction and to move towards professionalization. However, possessing abstract knowledge alone isn't enough; one must apply the abstract knowledge in unique ways to further contribute to the professionalization of respiratory therapy.

\section{Legitimacy}

The foundation of abstract knowledge in respiratory therapy is the therapeutic application of mechanical ventilators and other technology-based respiratory care therapeutics. Notably, the constant evolution, refinement, increased sophistication, and expanded clinical application of mechanical ventilation has been a driving force in developing RTs' abstract body of knowledge, which legitimizes the work (and profession) of RTs [44]. Since the innovation of PEEP in the 1970s, RTs have successfully defended and innovated within the domain of their unique abstract knowledge relating to the application and management of mechanical ventilation [45]. RTs have successfully applied such abstract knowledge to other clinical practice areas, whose foundations are linked to mechanical requirements (e.g., anesthesia, sleep lab, home ventilation case management), and have consistently ensured that their approach to mechanical application is always patient-centred, holistic, and therapeutic [46].

Despite RTs' successful application of abstract knowledge to other clinical venues, further developments are necessary if the profession is to continue to innovate. To impact respiratory therapy practice and research, RTs and researchers will need to develop the ability to apply respiratory therapy knowledge from different disciplines (e.g., epidemiology, social science). This can be achieved through deeper considerations of a range of knowledge paradigms (e.g., post-positivism, constructivism), which legitimize sources of knowledge other than those obtained through, for example, quantitative methodologies (i.e., using qualitative and mixed-method methodologies). Doing so will require that they make explicit their views on what can be learned (ontology), whether that knowledge is considered to be valid or legitimate (epistemology), and how that knowledge is obtained (methodology) [47]. Currently, this breadth and depth of unique respiratory therapy knowledge is lacking.

\section{Research}

Abstract knowledge is also used to conduct research. The primary aim of research is to create new knowledge in a way that shapes and changes the current and future professional knowledge base (e.g., developing new ways that professionals may treat or diagnose the problems of professional work) [12]. Information about RTs whose primary mandate is to conduct research is scarce. Few RTs hold any research-related positions, and no data exist on if and how they receive financial support to conduct research $[48,49]$.

According to the results of a cross-sectional study by Martins and Kenaszchuk [50], RTs strongly believe that they should be the ones who formulate and test hypotheses on topics likely to advance respiratory therapy practice. Indeed, RTs are the end-users of the technological or 
therapeutic modality and are thus well-suited to generate questions and add to RTs' knowledge base [50]. Some suggestions to support RTs' efforts to further professionalize include (i) professional organizations or governing bodies to advocate for academic or clinical positions for RTs that hold protected time for research and (ii) capacity-building activities for RTs interested in research using empirically supported frameworks (see Matus [51] for an overview). Respiratory care research led by RTs can play a significant role in contributing to abstract and evidence-informed knowledge in the profession, further legitimizing the work RTs do.

\section{Instruction (higher education)}

Abstract knowledge is particularly useful for developing and promoting higher education for RTs [12]. As mentioned in the historical overview, the original Canadian RTs' education level was deemed appropriate at the college-diploma level. Today, official professional statements have advocated for raising the entry-level diploma training to an undergraduate degree to meet the complex requirements of the health care environment and to remain competitive compared with other allied health professions [52-54]. Additionally, in Canada, there is no graduate education for RTs. Comparatively, in the United States, 13 programs offer graduate degrees in respiratory therapy; however, there are no available doctoral-level programs [55]. The argument for developing higher education needs to be supported by empirical evidence showing the benefits while also acknowledging societal, economic, and socio-political trends requiring higher levels of education in its RTs.

Using Abbott's theory [12], we can begin to see how all levels of higher education function within the complex system of professions. In addition to educating the next generation of health care professionals, higher education contributes to developing abstract knowledge and to the development of a profession. The current curricula for respiratory therapy training are loaded with the foundational knowledge, skills, and attributes required by students to function as a professional in the current health care system. However, core curricula will need to be revised to include training in research methods, scientific writing, and the principles of science, which contributes to developing abstracting knowledge for respiratory therapy [56-59]. In the current North American educational system, the first step is an undergraduate degree in respiratory therapy (i.e., B.RT) [60]. Undergraduate degrees introduce students to a broader range of competencies directly related to the profession and its functioning within the system (e.g., public health, health policy, leadership, etc.) [61]. For example, while undergraduate medicine students learn about anatomy and diagnosis, they integrate principles deemed essential for Canadian physicians (e.g., health policy, research) outlined by the CanMEDS competency framework [62].

Undergraduate programs are designed to include space to integrate topics such as research that may contribute to the growth of a profession, including potentially exploring career directions, building transferable skills, learning how to publicly advocate for and defend the work of RTs, and create knowledge to impact patient care [63-65]. Graduate respiratory therapy degrees (e.g., MSc. RT) promote RTs to develop advanced practice and integrate introductory research skills in their practice, enabling graduates to enter the workforce with advanced competencies [66-68].

Developing advanced professional knowledge that optimizes and bridges the research-practice gap is the main purpose of professional doctorates (e.g., Doctor of Nursing Practice (DNP), Doctor of Occupational Therapy (OTD)) [38, 69, 70]. These programs build upon a foundation of knowledge gained during graduate studies and further focus on the development of scholarly practitioners and their ability to successfully apply and develop theory related to everyday problems of professional practice within the workplace [71]. Although professional doctorates have a strong focus on advanced practice, training in and contribution to research has the potential to increase the use of evidence in practice. Graduates of professional doctorates are in a unique position to apply and extend knowledge in areas such as quality improvement, interprofessional collaboration, patient outcomes, health policy legislation, and advocacy as leaders in evidence-informed respiratory therapy practice $[72,73]$. However, as Abbott indicated, professional practice is not the only source of knowledge [12]. All aspects of knowledge (e.g., practical knowledge, theoretical knowledge) should be developed concurrently to support the abstraction of knowledge. The Doctor of Philosophy degree (Ph.D.) can be used to help professionals contribute to their profession on a theoretical and conceptual level rather than on an immediately practical one. For example, Ph.D. graduates in respiratory therapy may focus on the profession on a philosophical level by considering "why" and "how" types of research questions and by challenging existing knowledge and professional assumptions. Each degree contributes distinct yet complementary knowledge to a profession; this knowledge serves as the foundation of abstract knowledge and, as such, supports the professionalization of the profession [12].

\section{Professionalization, jurisdiction, and professional autonomy in respiratory therapy}

Professional autonomy is defined as having control over one's profession, the professional's work, and jurisdiction of a field of expertise [74]. Although professional autonomy is foundational for professional power and professionalization within modern society, it is constantly evolving $[12,75,76]$. Professional autonomy is gained, negotiated, and potentially lost depending on the profession's relationship with society $[22,77]$. According to Abbott, possessing a degree of professional autonomy means successfully achieving a jurisdiction $[78,79]$. In the subsequent paragraphs, we use the terms jurisdiction and professional autonomy interchangeably to discuss the professional autonomy of RTs with regards to their professionalization.

The first step towards securing a jurisdiction involves finding a vacant area of work to control, which may happen for numerous reasons (e.g., social or technological evolution) [12]. RTs benefited from a new jurisdiction formed by technological advancements (i.e., positive pressure mechanical ventilators) during Canada's polio epidemic's management. Physicians successfully argued that a new profession was needed to manage this new technology; specifically, they recommended that new experienced technicians had to be trained to assist physicians "since, by and large, interns, nurses and other paramedical personnel are not trained to carry out these specialized duties" [14]. We will discuss RTs' jurisdictional claim in the three areas outlined by Abbott [12]: the workplace, the legal system, and public opinion.

\section{Workplace}

Spurred by concrete needs, resources, and other workplace contextual circumstances, newly developing jurisdictions begin in the professional world (i.e., the workplace) [12]. During the 1950s, physicians had considerable interest in administering oxygen therapy to patients. However, because of the absence of medical gas pipeline systems, there was a need for the delivery of oxygen cylinders and related oxygen equipment to the patient's bedside $[13,45]$. As the physician's demands for oxygen services grew, RTs' jurisdiction also grew. This jurisdictional growth was in large part caused by physicians' actions as the dominating health care professional. Rather than physicians performing the labor-intensive work themselves, they decided to delegate (but remain in control of) the routine application of oxygen work to a separate occupation. The original tasks of RTs (e.g., delivering oxygen tanks) were deemed too simple given the nature and level of physicians' expertise. The RTs' work was labour intensive, using technical skills to provide safe oxygen service; the need for any medical knowledge or expertise was minimal [13].

Delegating jurisdictional control of the routine application of oxygen work was advantageous for physicians as it enabled them to retain a major influence over RTs' growth and independence [12, 77]. This type of jurisdictional control is called subordination [11, 80]. The negative connotation of subordination notwithstanding, physicians' involvement in developing the RTs' workplace jurisdiction was key in the professionalization of respiratory therapy in Canada. Physicians held a vision for cardio-respiratory care that included a new type of personnel, resulting in the creation of trained employees to help them attain this goal [13-15]. Physicians' support helped create an initial foothold in the profession's jurisdiction and constituted the first step towards professionalization. Despite the support that RTs received from their local physicians, 
they recognised that to evolve as a profession they need to develop their jurisdiction in other, larger areas such as the legal system and public opinion.

\section{Legal}

Without legal protection (i.e., statutory rights, administrative structure), a health care practitioner's right to claim a specific jurisdiction is more vulnerable to challenges from other professions. RTs successfully obtained a jurisdiction in the workplace when they began providing oxygen therapy and managing mechanical ventilators. Despite their success in the workplace, RTs' jurisdiction was at risk when their work became more routine, most notably in the delivery of aerosol medication [11]. Nurses lobbied to gain control of the routine delivery of aerosol medication to strengthen their own position as professionals. They contended to claim the work of determining doses, monitoring patients, and choosing the nebulizers used to deliver the drugs. These developments in the nursing profession resulted in a loss of workplace jurisdiction for RTs $[11,13]$. Despite these setbacks, more physicians made requests for the work of RTs in areas such as post-operative and intensive care [11]. It was clear that because of the increased reliance on RTs' skills, RTs had to move beyond the local workplace jurisdiction and legally (and more permanently) secure their jurisdiction.

To claim a legal jurisdiction, a group of health care practitioners needs to organize itself into a single, identifiable association [12]. Two distinctions are made here; the first is "being organized" and the second is "possessing a membership to their association". When a profession is strongly organized, they become better at mobilizing and controlling its members in an effort to assure the public's concerns of trustworthy work, leading to more effective claims of jurisdictions. The second is "the association". Professional associations (formed at the local or national level) advocate for the interest of their members, support capacity building within the profession, and lobby policymakers. In contrast, the regulatory body protects the public's interest [81]. In respiratory therapy, Manitoba became the first province in 1981 to form a provincial organized regulatory body to advocate for obtaining legislative protection, the privilege of self-regulation, the control of work, and jurisdiction. Since then, eight more provincial regulatory bodies followed (Table 1) [82]. Legislation relates to a law or laws that describe the extent of legal authority delegated to the profession; it draws a boundary or border around the profession [83]. It essentially acknowledges the profession, the expertise, and the body of knowledge and gives it the privilege of self-regulation. Across the provinces and territories of Canada, the respiratory therapy profession is legislated in eight out of 11 provinces (Table 1). The provincial regulatory bodies operate under a model of statutory self-regulation. Self-regulation refers to a professional organization's powers to set a framework of rules that holds its members accountable $[84,85]$. Self-regulation is a social contract between the profession and society where legislation allows the profession to set, within broad limits, its own standards. In return, patients receive an augmented level of standardized care [84].

It is important to note that some professions might not yet have achieved legislation in their respective location of practice for reasons such as an insufficient number of members, adequate oversight from employers, and lack of perceived benefit for quality of patient care. Without one or more of these reasons, a profession will not earn the right to self-regulate [86].

As part of the delegated authority, self-regulated professions are (first and foremost) entrusted with ensuring the safety and interest of the public. It is not to support the profession or individual members. Regulatory bodies ensure patient safety by establishing entrance requirements, mandating continuing education and professional development programs, developing a code of ethics, and developing and updating practice standards. Regulatory bodies also implement procedures to address complaints and allegations of professional misconduct. These administrative standards and accountability instituted for the public's interest and safety support the profession's jurisdiction [83].

Regulations play an important role in facilitating-and sometimes limiting-the jurisdiction of a profession. Regulations place boundaries on work that professions can and cannot do, which is more commonly referred to as a scope of practice [87]. According to this, autonomy refers to the ability to act according to one's knowledge and judgement, providing care within the full scope of practice as defined by existing professional, regulatory, and organization rules [88]. Autonomy does not and cannot mean full independence [89]. Autonomy is enacted within the context and boundaries of an interdependent health care team. RTs work in a complex system, with physicians often exerting some degree of dominance in the decision-making in the workplace [87, 89-92]. Essentially, a status of self-regulation removes a profession's constant oversight and direction by a third party (e.g., physicians in the case of RTs) and confers the oversight to members of that profession a degree of autonomy to provide care in a manner that is consistent with the public's best interest.

Self-regulation is a privilege granted by the government based on the public's trust. Trust and jurisdiction are tenuous concepts often influenced by social environments. Some argue that self-regulation is a

\section{TABLE 1}

Respiratory therapy legislation

\begin{tabular}{|c|c|c|}
\hline Province or Territory & Regulatory body & Governing legislation \\
\hline Ontario & College of Respiratory Therapy of Ontario (CRTO) & $\begin{array}{l}\text { Regulated Health Professions Act; Respiratory Therapy } \\
\text { Act, } 1991 \text { and regulations under the Act }\end{array}$ \\
\hline Alberta & College and Association of Respiratory Therapists of Alberta (CARTA) & $\begin{array}{l}\text { Health Professions Act, Revised Statutes of Alberta } \\
\text { (R.S.A) } 2000 \text { serves as umbrella legislation for multiple } \\
\text { health professions. }\end{array}$ \\
\hline Manitoba & Manitoba Association of Registered Respiratory Therapists (MARRT) & Registered Respiratory Therapists Act C.C.S.M. c. R115 \\
\hline Québec & Ordre professionnel des Inhalothérapeutes du Québec (OPIQ) & $\begin{array}{l}\text { Respiratory therapy is one of the professions regulated } \\
\text { under the Professional Code, R.S.Q., chapter C- } 26 \text {. }\end{array}$ \\
\hline Nova Scotia & Nova Scotia College of Respiratory Therapists (NSCRT) & $\begin{array}{l}\text { Respiratory Therapists Act, S.N.S. 2007, c. } 13 \\
\text { Respiratory Therapists' Regulations }\end{array}$ \\
\hline New Brunswick & New Brunswick Association of Respiratory Therapists (NBART) & An Act Respecting Respiratory Therapists 2009 \\
\hline Saskatchewan & Saskatchewan College of Respiratory Therapists (SCRT) & $\begin{array}{l}\text { The Statutes of Saskatchewan, (2006) } \\
\text { The Respiratory Therapists Act }\end{array}$ \\
\hline Newfoundland and Labrador & $\begin{array}{l}\text { The Newfoundland and Labrador College of Respiratory Therapists } \\
\text { (NLCRT) }\end{array}$ & $\begin{array}{l}\text { Health Professions Act } \\
\text { Respiratory Therapists Regulations }\end{array}$ \\
\hline Prince Edward Island & None & $\begin{array}{l}\text { Professional credential overseen by the Canadian } \\
\text { Society of Respiratory Therapists (CSRT) }\end{array}$ \\
\hline British Columbia & None & Professional credential overseen by CSRT \\
\hline Prince Edward Island & None & Professional credential overseen by CSRT \\
\hline Yukon & None & Professional credential overseen by CSRT \\
\hline Nunavut & None & Professional credential overseen by CSRT \\
\hline Northwest Territories & None & Professional credential overseen by CSRT \\
\hline
\end{tabular}


monopolistic endeavour by professions; they do not serve the public's best interest and that the focus should be on a new model of care (e.g., a model that includes lay people in leadership positions) [93, 94]. The removal or significant modification of a self-regulation model and subsequent regulation redesign may cause a significant paradigm shift across the health professions, potentially impacting the limits of jurisdiction and, therefore, the professionalization of those professions. However, it is unknown whether this paradigm shift would be a positive or negative change.

\section{Public}

The public's opinion about the profession is the third element in professionalization. Professionals aim to build their image in the public's eye by attracting the public's sympathy and support for the work that they do and their approach to problem solving [12]. The more public support a profession possesses, the stronger jurisdiction it will hold. No documented literature exists regarding the public's perception and knowledge of RT compared with, for example, the nursing literature, which contains numerous empirical reports of patient satisfaction, patient perception, and self-concept, which contribute to enhancing the public's opinion of the nursing profession and reinforcing their jurisdictional claims [95-97].

Due to the critical nature of the RTs' role, they are often at the forefront of public health emergencies, notably the severe acute respiratory syndrome (SARS) outbreak in 2003, the H1N1 influenza pandemic of 2009, and now the COVID-19 global pandemic in 2020. In all of these scenarios, RTs deliver acute and critical care services such as diagnostic testing, respiratory therapeutics, and emergency airway management and mechanical ventilatory support [98]. The recent COVID-19 pandemic has bolstered the respiratory therapy profession's public perception and placed a critical eye on the profession, the work they perform, and their contribution to worldwide health. Media reports and marketing campaigns are emphasizing the importance of RTs' work, methods of problem-solving, and jurisdiction [6-10]. Although currently uncertain, the enhanced focus on RTs might potentially translate into new areas of jurisdiction. As the respiratory therapy profession emerges from the COVID-19 pandemic with a heightened level of recognition and a clear demonstration that its work has greatly benefitted the public's interest, RTs may be well-positioned to advocate for a greater jurisdiction. Already, conversations are beginning regarding how RTs may contribute more efficient care with additional expertise in future jurisdictions. Some examples might include advanced practice roles (e.g., cardiovascular specialists, case management), primary care, health systems leadership, and practice in new settings (e.g., public health) [99-101]. These new jurisdictional areas of practice might represent the continuation of professionalization of respiratory therapy.

\section{Moving forward}

Based on Abbott's theoretical perspective [12], RTs can rightly justify their position as members of a profession. However, as we explored in this paper, professionalization is an ongoing negotiative process and is worthy of ongoing attention and nurturing. Many key events in the professionalization of RTs in Canada, including the advent of new technology, consistent medical support, and the organization of the profession, highlight how oxygen orderlies became the profession of respiratory therapy. Notwithstanding the foundational events, RTs need to acknowledge that professionalization is a dynamic and continuous process that requires creative changes to innovate within the profession and to support future efforts to reinforce their position as members of a profession. Throughout this paper, we offer suggestions for how RTs can contribute to respiratory therapy professionalization.

There is a need to increase and strengthen the abstract knowledge of the respiratory therapy profession. Abstract knowledge is of value to a profession and can be strengthened in three ways: promoting higher education, conducting research, and increasing the professions' legitimacy. We contend that the respiratory therapy profession would benefit from raising the current entry-level diploma degree to an undergraduate degree. Existing respiratory therapy educational curricula generally focus on the minimum competencies required to function as professionals. The aim of an undergraduate degree is to introduce learners to a broader range of competencies directly related to the profession and its functioning within the health care system (e.g., public health, health policy, leadership, research skills, etc.) to expand the clinical reasoning and broaden the impact and influence of RTs. By virtue of the competencies and corresponding content included in many existing RT educational programs, RTs may be far from maximizing their possible contributions to advancing respiratory therapy knowledge, and as such, may be limited in their potential to optimize patient care and meet the needs of a highly complex health care environment [56]. Enhancing the entry-level educational standards of respiratory therapy training may enable certain RTs to dedicate their careers to building abstract knowledge in the profession through conducting research for example.

There is a related need to create research-related positions (whether in clinical practice settings or in educational institutions) specific for RTs whose primary mandate is respiratory care research. Respiratory care research led by RTs can play a significant role in contributing to abstract knowledge in the profession. Finally, RTs who do (or will eventually) conduct respiratory care research need to widely explore respiratory therapy knowledge in many distinct ways to enhance the legitimacy of the knowledge. Examples of this distinction include applying and exploring respiratory therapy knowledge through the lens of a range of knowledge paradigms (e.g., post-positivism, constructivism), using different methodologies (qualitative, quantitative, and mixed method) and drawing from different academic disciplines (e.g., epidemiology and social sciences).

In Canada, for the most part, RTs possess jurisdictional professional autonomy evidenced by strong provincial administrative structures and the statutory right to self-regulate; however, the permanence of a strong administrative structure and self-regulation cannot be [93]. The calls for an overhaul of the professional self-regulation system are in response to perceptions that regulatory bodies may not be optimally protecting the public $[93,94]$. The ongoing need for abstract knowledge will be required to safeguard and advance the legal aspect of jurisdiction by linking evidence and concepts about care and expectations with frontline practice. The role of regulatory bodies could be expanded to support research, activities, innovations, and quality improvement initiatives that build an understanding of the safe and competent care RTs are equipped to provide.

Finally, we contend that the weakest aspect of jurisdiction in the respiratory therapy profession derives from the public's opinion. Before the COVID-19 pandemic, personal exchanges with laypeople often began with, "A respiratory therapist? I've never heard of that; so, you're like a nurse?" A major unintended consequence of the pandemic was the immediate propulsion of the respiratory therapy profession into the limelight. Media reports, medical reports, and marketing campaigns began emphasizing the importance of RTs' work, their method of problem-solving, and jurisdiction. This renewed emphasis on the respiratory therapy profession and the focus on the work they do and how that may contribute to more efficient care might translate into further professionalization opportunities. RTs need to begin producing evidence that demonstrates improved health outcomes when RTs are involved, further informing and convincing the public and policymakers of the importance of this profession [102-104].

\section{DISCLOSURES}

\section{Acknowledgement}

This work was completed in partial fulfillment of MZ's doctoral degree at the School of Physical and Occupational Therapy, McGill University. $\mathrm{MZ}$ would like to acknowledge the feedback provided on early drafts of this manuscript by Shawna Strickland, PhD, CAE, RRT, RRT-NPS, RRT-ACCS, AE-C, FAARC and Kevin Taylor, MBA, RRT. 


\section{Contributors}

MZ conceptualized the idea, drafted the manuscript, provided feedback on manuscript drafts, and read and approved the final manuscript. $A B$, PN, AW, and AT provided content expertise, provided feedback on manuscript drafts, and read and approved the final manuscript.

\section{Funding}

McGill University Faculty of Medicine and Health Sciences Max E. Binz Fellowship.

\section{Competing interests}

MZ and AW are members of CJRT's editorial board and were not involved with any decisions about the manuscript. All other authors declare no conflict of interest.

\section{Ethical approval}

Ethical approval was deemed not to be necessary as the data is publicly available literature.

\section{REFERENCES}

1. US Bureau of Labor Statistics. Occupational employment and wages-respiratory therapists. 2019. Available at: https://www.bls.gov/oes/2018/ may/oes291126.htm (Accessed August 8, 2020).

2. Canadian Institute for Health Information. Canada's health care providers, 2014 to 2018 - data tables. Ottawa, ON: CIHI; 2020. Available at: https://www.cihi.ca/en/health-workforce (Accessed October 15, 2020).

3. Canadian Society of Respiratory Therapists. Respiratory therapist. 2020. Available at: https://www.csrt.com/wp-content/uploads/Whatis-an-RT_2019.pdf (Accessed August 8, 2020).

4. Li J, Zhan QY, Liang ZA, et al. Respiratory care practices and requirements for respiratory therapists in Beijing intensive care units. Respir Care 2012;57(3):370-6. doi: 10.4187/respcare.01093.

5. Shevade MS, Yeravdekar RC, Salvi SS. A cross-sectional survey of practice patterns and selected demographics of respiratory therapists in India. Respir Care 2021;66(1):66-72. doi: 10.4187/respcare.07823.

6. McCoy C. How respiratory therapists keep COVID-19 patients alive. In Gurney M, ed. TVO. TVO.org; 2020. Available at: https://www.tvo. org/article/how-respiratory-therapists-keep-covid-19-patients-alive (Accessed November 5, 2020).

7. Hester TB, Cartwright JD, DiGiovine DG, et al. Training and deployment of medical students as respiratory therapist extenders during COVID-19. ATS Scholar 2020;1(2):145-51. doi: 10.34197/ats-scholar. 2020-0049PS.

8. American Association for Respiratory Care. Respiratory therapists: warriors in the fight against COVID-19. 2020. Available at: https://www. aarc.org/nn20-respiratory-therapists-warriors-in-the-fight-againstcovid-19/ (Accessed August 29, 2020).

9. Collie M. Respiratory therapists may be the "best kept secret" in the fight against coronavirus. Global News; 2020. Available at: https:// globalnews.ca/news/6857158/coronavirus-respiratory-therapist/ (Accessed November 1, 2020).

10. Johnson P. Focus on respiratory therapists during COVID-19 outbreak. Global News; 2020. Available at: https://globalnews.ca/ video/6734313/focus-on-respiratory-therapists-during-covid-19-outbreak (Accessed November 1, 2020).

11. Prud'homme J. "Professional Techs": machines, technical skills and professional aspirations in hearing prosthetics and respiratory care in Quebec, 1950-1990. Sci Can 2011;33(1):71-94. doi: 10.7202/1000845ar.

12. Abbott A. The system of professions: an essay on the division of expert labor. Chicago, IL: University of Chicago Press; 1988.

13. Andrews M. The early years - a reflective history of the Canadian Society of Respiratory Therapists. Ottawa, ON: Canadian Society of Respiratory Therapist; 2006.

14. Noble A. Training for inhalation therapy technicians in Canada. Can Med Assoc J 1962;87:818.

15. McCaughey TJ. Anaesthetic technicians in the Province of Québec. Can Anaesth Soc J 1975;22(1):106-10. doi: 10.1007/BF03004826.

16. Nickerson J. An examination of the role of the Canadian Journal of Respiratory Therapy. Can J Respir Ther 2013;49(4):5-6.

17. Cooper JE. Reflections on the professionalization of occupational therapy: time to put down the looking glass. Can J Occup Ther 2012;79(4):199-210. doi: 10.2182/cjot.2012.79.4.2.
18. Siegrist H. Professionalization as a process: patterns, progression and discontinuity. In Burrage M, Torstendahl R, eds. Professions in theory and history: rethinking the study of the professions. London, UK: Sage; 1990. p. 172-202.

19. Keogh J. Professionalization of nursing: development, difficulties and solutions. J Adv Nurs 1997;25:302-8. doi: 10.1046/j.1365-2648.1997. 1997025302.x.

20. Hamilton PM. Realities of contemporary nursing. New York: AddisonWesley Nursing; 1992.

21. Foote NN. The professionalization of Labor in Detroit. Am J Sociol 1953;58(4):371-80. doi: 10.1086/221174.

22. Larson MS. The rise of professionalism: a sociological analysis. Berkeley, CA: University of California Press; 1977.

23. Clouston TJ, Whitcombe SW. The professionalisation of occupational therapy: a continuing challenge. Br J Occup Ther 2008;71(8):314-20. doi: $10.1177 / 030802260807100802$.

24. Amzat J, Razum O. Sociology and health. In Medical sociology in Africa. 2014. p. 1-19.

25. Martimianakis MA, Maniate JM, Hodges BD. Sociological interpretations of professionalism. Med Educ 2009;43(9):829-37. doi: 10.1111/j.1365-2923.2009.03408.x.

26. Furness C. The system of professions. Educ Inf 2019;35(3):353-6. doi: 10.3233/efi-190271.

27. Lybeck E. Ajurisdiction. Theory Soc 2019;48(1):167-91. doi: 10.1007/ s11186-018-09337-x.

28. Nolin J. In search of a new theory of professions. Högskolan: University of Borås; 2008.

29. Boon H, Welsh S, Kelner M, Wellman B. CAM practitioners and the professionalisation process: a Canadian comparative case study. In The mainstreaming of complementary and alternative medicine. 1st ed. Routledge; 2003.

30. Heckman JD. Let's keep our eye on the sparrow*. J Bone Joint Surg 1998;80(6):775-81. doi: 10.2106/00004623-199806000-00001.

31. Nancarrow SA, Borthwick AM. Dynamic professional boundaries in the healthcare workforce. Sociol Health Illn 2005;27(7):897-919. doi: 10.1111/j.1467-9566.2005.00463.x.

32. Kroezen M, van Dijk L, Groenewegen PP, Francke AL. Knowledge claims, jurisdictional control and professional status: the case of nurse prescribing. PLoS One 2013;8(10):e77279. doi: 10.1371/journal.pone.0077279.

33. Freidson E. Professionalism, the third logic. Chicago, IL: The University of Chicago Press; 2001.

34. Morris PWG, Crawford L, Hodgson D, Shepherd MM, Thomas J. Exploring the role of formal bodies of knowledge in defining a profession - the case of project management. Int J Proj Manag 2006;24(8):71021. doi: $10.1016 /$ j.ijproman.2006.09.012.

35. Cruess SR, Johnston S, Cruess RL. "Profession": a working definition for medical educators. Teach Learn Med 2004;16(1):74-6. doi: 10.1207/ s15328015tlm1601_15.

36. Kirk LM. Professionalism in medicine: definitions and considerations for teaching. Proc (Bayl Univ Med Cent) 2007;20(1):13-16. doi: 10.1080/08998280.2007.11928225.

37. Moloney MM. Professionalization of nursing: current issues and trends. 2nd ed. Philadelphia PA: J.B. Lippincott Company; 1992.

38. LaMere K. Reframing the conversation about doctoral education: professionalization and the critical role of abstract knowledge. Iridescent 2012;2(1):40-9. doi: 10.1080/19235003.2012.11428502.

39. Evans L. Professionalism, professionality and the development of education professionals. Br J Educ Stud 2008;56(1):20-38. doi: 10.1111/j.1467-8527.2007.00392.x.

40. Adams TL. Profession: a useful concept for sociological analysis? Can Rev Sociol 2010;47(1). doi: 10.1111/j.1755-618X.2010.01222.x.

41. Heap R. Physiotherapy's quest for professional status in Ontario, 1950-80. Can Bull Med Hist 1995;12(1):69-99. doi: 10.3138/ cbmh.12.1.69.

42. Martins SC. Chiropractic and the social context of medical technology, 1895-1925. Technol Cult 1993;34(4):808-34. doi: 10.2307/3106416.

43. Gattinoni L, Collino F, Maiolo G, et al. Positive end-expiratory pressure: how to set it at the individual level. Ann Transl Med 2017;5(14):288. doi: $10.21037 / \mathrm{atm} .2017 .06 .64$.

44. Kacmarek RM. The mechanical ventilator: past, present, and future. Respir Care 2011;56(8):1170-80. doi: 10.4187/respcare.01420.

45. Kacmarek RM. Mechanical ventilation competencies of the respiratory therapist in 2015 and beyond. Respir Care 2013;58(6):1087-96. doi: 10.4187 /respcare. 02546 . 
46. Chartrand L. Individualism and the decision to withdraw life support. Societies 2018;8(4). doi: 10.3390/soc8040117.

47. Varpio L, MacLeod A. Philosophy of science series: harnessing the multidisciplinary edge effect by exploring paradigms, ontologies, epistemologies, axiologies, and methodologies. Acad Med 2020;95(5):686-9. doi: 10.1097/ACM.0000000000003142.

48. Pierson DJ. Research and publication in respiratory care. Respir Care 2004;49(10):1145-8.

49. Nonoyama ML, Mathur S, Herbert R, Jenkins H, Lobchuk M, McEvoy $\mathrm{M}$. Past, present and future of respiratory research: a survey of Canadian health care professionals. Can J Respir Ther 2015;22(5). doi: 10.1155/2015/968450.

50. Martins C, Kenaszchuk C. Research capacity of respiratory therapists: a survey of views, opinions and barriers. Can J Respir Ther 2013;49(4):15-19.

51. Matus J, Walker A, Mickan S. Research capacity building frameworks for allied health professionals - a systematic review. BMC Health Serv Res 2018;18(1):716. doi: 10.1186/s12913-018-3518-7.

52. Entry to respiratory therapy practice 2030 [press release]. 2019. Available at: https://www.aarc.org/wp-content/uploads/2019/09/issue-paper-entry-to-respiratory-therapy-practice-2030.pdf (Accessed November 11, 2020).

53. CSRT position statement on baccalaureate degree as entry-to-practice [press release]. 2019. Available at: https://www.csrt.com/wp-content/ uploads/Degree-ETP-Position-2019.pdf (Accessed November 11, 2020).

54. Demande de rehaussement du diplôme donnant ouverture au permis d'inhalothépeute [press release]. 2020. Available at: https://www.opiq.qc.ca/ wp-content/uploads/2020/07/opiq_e-memoire_rehaussement_VF.pdf.

55. Coalition for Baccalaureate and Graduate Respiratory Therapy Education. Master's degree with a respiratory therapy/respiratory care major. 2020. Available at: http://www.cobgrte.org/graduateprograms. html (Accessed August 16, 2020).

56. Barnes TA, Kacmarek RM, Kageler WV, Morris MJ, Durbin CG, Jr. Transitioning the respiratory therapy workforce for 2015 and beyond. Respir Care 2011;56(5):681-90. doi: 10.4187/respcare.01169.

57. Hess DR. Evidence-based respiratory care. Respir Care 2021;66(7):110519. doi: $10.4187 /$ respcare.08950

58. Branson RD, Kallet RH. Creating a process of research in respiratory care. Respir Care 2021;66(8):1363-4. doi: 10.4187/respcare.09367.

59. Jager F, Vandyk A, Jacob JD, et al. The Ottawa model for nursing curriculum renewal: an integrative review. Nurse Educ Today 2020;87:104344. doi: 10.1016/j.nedt.2020.104344.

60. Becker E. Point of view: promoting baccalaureate completion among respiratory therapists. Respir Care Educ Annu 2003;12:11.

61. Institute of Medicine. The future of nursing: leading change, advancing health. Washington, DC: The National Academies Press; 2011. p. $163-220$

62. University M. MDCM program learning objectives. 2021. Available at: https://www.mcgill.ca/ugme/mdcm-curriculum-joint-programs/curriculum-structure/program-learning-outcomes (Accessed December 1, 2020).

63. Aiken LH, Sloane DM, Bruyneel L, et al. Nurse staffing and education and hospital mortality in nine European countries: a retrospective observational study. Lancet 2014;383(9931):1824-30. doi: 10.1016/ s0140-6736(13)62631-8.

64. Petrella J, Jung A. Undergraduate research: importance, benefits, and challenges. Int J Exerc Sci 2008;1(3):91-5.

65. Helgoy KV, Smeby JC, Bonsaksen T, Rydland Olsen N. Research-based occupational therapy education: an exploration of students' and faculty members' experiences and perceptions. PLoS One 2020;15(12):e0243544. doi: 10.1371/journal.pone.0243544.

66. Loma Linda University Health. Master of Science in Respiratory Care (MSRC). Loma Linda University; 2020. Available at: https://alliedhealth.llu.edu/academics/cardiopulmonary-sciences/respiratory-care/ respiratory-care-masters (Accessed October 10, 2020).

67. Boise State University. Master of science in respiratory care. Boise State University; 2020. Available at: https://www.boisestate.edu/respiratorycare/msrc/ (Accessed October 6, 2020).

68. Rush University. Master of science in respiratory care. 2020. Available at: https://www.rushu.rush.edu/college-health-sciences/academic-programs/master-science-respiratory-care (Accessed October 7, 2020).

69. Tobbell DA. Nursing's boundary work: theory development and the making of nursing science, ca. 1950-1980. Nurs Res 2018;67(2):63-73. doi: 10.1097/NNR.0000000000000251.

70. DiBartolo MC. Philosophy of science in doctoral nursing education revisited. J Prof Nurs 1998;14(6):350-60. doi: 10.1016/S8755-7223 (98)80077-X.
71. Maxwell T. From first to second generation professional doctorate. Stud High Educ 2003;28(3):279-91. doi: 10.1080/03075070309292.

72. Costley C, Lester S. Work-based doctorates: professional extension at the highest levels. Stud High Educ 2012;37(3):257-69. doi: 10.1080/03075079.2010.503344.

73. Taylor N, Maxwell T. Enhancing the relevance of a professional doctorate: the case of the doctor of education degree at the University of New England. Asia-Pac J Coop Educ 2004;5(1):60-9.

74. Karvinen-Niinikoski S, Beddoe L, Ruch G, Tsui M-S. Professional supervision and professional autonomy. Aotearoa N Z Social Work 2019;31(3):87-96. doi: 10.11157/anzswj-vol31iss3id650.

75. Coburn D. Medical dominance then and now: critical reflections. Health Sociol Rev 2014;15(5):432-43. doi: 10.5172/hesr.2006.15.5.432.

76. Brante T. Professions as science-based occupations. Prof Prof 2011;1(1). doi: $10.7577 /$ pp.v1i1.147.

77. Freidson E. Professional powers: a study of institutionalization of formal knowledge. Chicago, IL: The University of Chicago Press; 1986.

78. Shanahan T. A Discussion of autonomy in the relationship between the Law Society of Upper Canada and the University-Based Law Schools. Can J High Educ 2000;30(1):27-56. doi: 10.47678/cjhe. v30i1.183345.

79. Thompson MC. Professional autonomy of occupational health nurses in the United States. Workplace Health Saf 2012;60(4):159-65. doi: 10.1177/216507991206000404.

80. Twohig PL. Education, expertise, experience and the making of hospital workers in Canada, 1920-1960. Sci Can 2006;29(2):131-53. doi: 10.7202/800522ar.

81. Benton DC, Thomas K, Damgaard G, Masek SM, Brekken SA. Exploring the differences between regulatory bodies, professional associations, and trade unions: an integrative review. J Nurs Regul 2017;8(3):4-11. doi: 10.1016/S2155-8256(17)30154-0.

82. Blais P. Access issues regarding internationally educated health professionals and the respiratory therapy profession in canada. Montréal: The National Alliance of Respiratory Therapy Regulatory Bodies; 2008.

83. Newfoundland and Labrador Council of Health Professionals. What's self-regulation all about? NLCHP; 2014. Available at: https://nlchp. web.thentiaqa.com/wp-content/uploads/2019/10/MakingConnections-Vol-1-Spring-2014.pdf (Accessed August 23, 2020).

84. Davies C. Regulating the health care workforce: next steps for research. J Health Serv Res Policy 2004;9:55-61. doi: 10.1258/135581904322724149.

85. The College of Respiratory Therapists of Ontario. Regulated Health Professions Act Chapter 1 [Video File]. Oct 16, 2013. Available at: https://www.youtube.com/watch?v=kloI9ipYDDo\&list=SP5UXJ74E99DSTPUlp3t0gEZ8yjqKdfLiO (Accessed January 12, 2021).

86. Health Professions Regulatory Advisory Council. Mandate: about the Health Professions Regulatory Advisory Council (HPRAC). Government of Ontario; 2013. Available at: https://www.hprac.org/ en/about/mandate.asp (Accessed October 30, 2020).

87. Kelner M, Wellman B, Boon H, Welsh S. Responses of established healthcare to the professionalization of complementary and alternative medicine in Ontario. Soc Sci Med 2004;59(5):915-30. doi: 10.1016/j. socscimed.2003.12.017.

88. Weston MJ. Defining control over nursing practice and autonomy. J Nurs Adm 2008;38(9):404-8. doi: 10.1097/01.NNA.0000323960.29544.e5.

89. MacDonald C. Nurse autonomy as relational. Nurs Ethics 2002;9(2). doi: 10.1191/0969733002ne498oa.

90. Kenny DT, Adamson B. Medicine and the health professions:Issues of dominance, autonomy and authority. Aust Health Rev 1992;15(3):319-34.

91. Oshodi TO, Bruneau B, Crockett R, Kinchington F, Nayar S, West E. Registered nurses' perceptions and experiences of autonomy: a descriptive phenomenological study. BMC Nurs 2019;18:51. doi: 10.1186/ s12912-019-0378-3.

92. Elwood TW. Patchwork of scope-of-practice regulations prevent allied health professionals from fully participating in patient care. Health Aff (Millwood) 2013;32(11):1985-9. doi: 10.1377/hlthaff.2013.0530.

93. Motluk A. Self-regulation in health care professions comes under scrutiny. CMAJ 2019;191(33):E926-7. doi: 10.1503/cmaj.109-5790.

94. Van den Bergh R. Self-regulation of the medical and legal professions: remaining barriers to competition and the EC-law. In Pressure Groups, self-regulation and enforcement mechanisms; January 10-11, 1997; Milano.

95. Girvin J, Jackson D, Hutchinson M. Contemporary public perceptions of nursing: a systematic review and narrative synthesis of the international research evidence. J Nurs Manag 2016;24(8):994-1006. doi: 10.1111/jonm.12413. 
96. Schmidt LA. Patients' perceptions of nursing care in the hospital setting. J Adv Nurs 2003;44(4):393-9. doi: 10.1046/j.0309-2402.2003.02818.x.

97. Aiken LH, Sloane DM, Ball J, Bruyneel L, Rafferty AM, Griffiths P. Patient satisfaction with hospital care and nurses in England: an observational study. BMJOpen 2021;8(1). doi: 10.1136/bmjopen-2017-019189.

98. West A. Public health in Canada: evolution, meaning and a new paradigm for respiratory therapy. Can J Respir Ther 2013;49(4):7-10.

99. Alismail A, Lopez D. Clinical competencies in advanced practice respiratory therapy education: is it time to entrust the learner? Adv Med Educ Pract 2020;11:83-9. doi: 10.2147/AMEP.S239376.

100. Joyner RL, Jr., Strickland SL, Becker EA, et al. Adequacy of the provider workforce for persons with cardiopulmonary disease. Chest 2020;157(5):1221-9. doi: 10.1016/j.chest.2019.09.030.
101. Strickland SL, Varekojis SM, Goodfellow LT, et al. Physician support for non-physician advanced practice providers for persons with cardiopulmonary disease. Respir Care 2020. doi: 10.4187/respcare.07387.

102. Rickards T, Kitts E. The roles, they are a changing: respiratory therapists as part of the multidisciplinary, community, primary health care team. Can J Respir Ther 2018;54(4). doi: 10.29390/cjrt-2018-024.

103. Kollef MH. Evaluating the value of the respiratory therapist: where is the evidence? Focus on the Barnes-Jewish Hospital experience. Respir Care 2017;62(12):1602-10. doi: 10.4187/respcare.05807.

104. Kollef MH, Shapiro SD, Clinkscale D, et al. The effect of respiratory therapist-initiated treatment protocols on patient outcomes and resource utilization. Chest 2000;117(2):467-75. doi: 10.1378/ chest.117.2.467 